\title{
STUDY ABROAD, AS SEEN THROUGH THE EYES OF A PARTICIPANT
}

\section{K. D. Gangrade*}

\begin{abstract}
AL over India there is a gtowing awareness of the need for professional social workers and for their training. This is very much evident by a rising number of applications received for admission to schools of social work and a great demand for trained personnel to man different welfare programs and services. India has declared itself a welfare state and has taken a direct responsibility in promoting a number of welfare services for the benefit of the people. Both government and non-government agencies have been established, and each requires a qualified staff for the effective implementation of its program.
\end{abstract}

The profession of social work is very young in India. There are about twenty post-graduate schools, and the oldest one dates back to 1936 . Only a very few have completed their tenth anniversary. The Indian schools of social work are very much conscious of their responsibilities in the field of social welfare and of the demands made on them. They are also very much aware of their need to improve their standards and modify their training programs to meet the challenge of the time. This they want to achieve by staff development and improving their practices of admission. One of the steps taken by the schools in this direction is to send their staff to other countries in which the profession of social work has taken its roots and has developed a considerable body of theory and practice.

An important need is to have an opportunity for supervised field work. In India very young people with a very limited field experience enter into the profession and occupy a position in agencies with almost no supervision or guidance from the top, since they are the only trained personnel in the agency. Teachers in the schools are appointed just after their graduation, having had no work experience. Teachers in most of the schools are not only responsible for teaching and supervising students in field work but are required to give consultation to the agency supervisor where one exists. They also sometimes start agencies for various social services and welfare programs. Thus there is a great demand and expectation from the teacher in India in developing the profession of social work. And as long as facilities for advanced training are not available in our country, we will continue to send teachers and others abroad for training. This move- ment is facilitated and encouraged by scholarships made available through international agreements and programs of official and non-official organizations. The India Project sponsored by the Council on Social Work Education in the United States is such a program.

\section{The CSWE India Project}

The Government of India, seeing the importance of social work training, entered into an agreement with the Government of the United States whereby the latter would provide necessary facilities for training Indian participants in the States and sending technicians to give consultative service in the field of education for social welfare in India. As a consequence of this agreement, the American agency known as the International Cooperation Administration [now the Agency for International Development] and its Technical Cooperation Mission in India entered into a contract with the Council on Social Work Education - thus the CSWE India Project was born.

The American technicians are assigned by the Ministry of Education to the schools of social work which requested such a consultant in response to a proposal of the Ministry.

The Indian participant is selected by the head of the school of social work in India in consultation with the American technician, and a formal proposal is sent to the Ministry for approval and nomination. This procedure has been worked out so that participants who have had considerable experience and have demonstrated ability to develop theory and practice in the field of social work may be sent for advanced training. The technician assigned to the school is able to assess the needs of the school in general and of the participant in particular. The information which he has about training programs prevalent in his country makes it possible to come to a correct decision as to a suitable program for the participant.

In some instances the participant can be enrolled in a school where a faculty member of that institution has visited India and worked in Indian schools. This procedure to a certain degree meets the scepticism on the part of some who doubt the successful utilization of knowledge and techniques gained by the participant

\footnotetext{
- Mr. Gangrade earned his Master of Social Work degree at the Univer sity of Michigan in the United States as a participant in the CSWE India Project. He now is in charge of the Field Work Department of the Delhi School of Social Work, India. This article is reprinted with minor changes and with the permission of the Council on Social Work Education which published the original article br Mr. Gangrade with minor changes and with the permission of the Council on Social Work Education which published the original article
under the title "The India Project seen through the Eyes of a Delhi Participant" in Social Work Education. April, 1962.
} 
abroad. The contract also requires the participant to return to the home country within a prescribed period of training and serve the sponsoring school for a specific time. The idea behind this type of contract is to help the institution get immediate benefit from the participant in developing and strengthening its program.

\section{Experience of a Participant}

In I958-59 I was one of the participants to take part in the training program under the CSWE India Project, attending the School of Social Work of the University of Michigan. My program consisted of class lectures, seminars, panel discussions, field work and research, with group work as my major. In group work I had an advanced group work sequence. The emphasis in these courses was on group work as a problem-solving or a treatment process.

Classes in the school of social work were reasonably small and provided a good opportunity to participate in class discussions. The classes were conducted through discussion methods, and the teachers gave various reading assignments to enable the students to participate more effectively. The class discussions were very stimulating and gave much insight into the subject. The structure of the class was informal and, most of the time, students were given the very important role of leading the discussion, while teachers served as resource persons.

The content of the courses is designed to prepare social workers to meet the demand of the American social welfare scene, but an attempt is made to meet the needs of the foreign students by suitably modifying their training program. A number of assignments were given to see the applicability of certain concepts and principles to the Indian scene.

I was assigned for my field work training to an agency designed to serve problem areas. In the first term I was to get acquainted with agency structure, policies, procedures and programs; provide direct leadership to a group; and prepare a booklet of resources available in the community. This placement gave me an opportunity to work with an experienced supervisor and develop more insight into the practice of social group work. In the second semester I continued my work in the same agency and worked with another supervisor. He was the executive director of the agency, having considerable years of experience to his credit but having had no formal education in social work. My field work assignment in this term consisted of continued leadership of the last semester's group, assisting the executive director in drafting an agency manual, and work in an elementary school to develop a social work program.

In my field work assignments I enjoyed the experience of becoming well acquainted with agency structure, policies, procedures and programs. I also used this opportunity to make comparisons with social work practices in India.

I was regarded as a member of the agency staff and was required to attend and participate in all the staff meetings, including budget sessions. This is very rarely allowed in India. In a very few enlightened agencies students are allowed to attend as observers. The participation in the staff meetings helps one to feel that he has a say in decision- and policy-making processes of the agency.

The assignment of preparing a booklet of resources gave me a first working contact with staff members of other agencies. I had experiences of delay, unfulfilled promises, and the frustration of not being able to finish quickly a task which was not complex. Philosophically, I was able to dilute my disappointment, as I of course had similar experiences at home.

I was also given a group of teen-age boys from a school as a part of my field work assignment. This was a "made" group, as the members were referred by school authorities as those having some adjustment problems, which, it was felt, could be modified by experiences in a small group. I did not feel this assignment as exceptionally challenging since, in India, I had enjoyed the responsibility of direct leadership in many difficult situations. However, I enjoyed working with the children, and was very glad to find that if one had enough program skills and knowledge of dynamics of human behavior, it did not matter from what culture one had come. I was able to develop an excellent relationship with the members of the group. This on the whole was a fascinating experience, and it was certainly educative to work with a group of boys drawn from white and Negro families.

In India field work in social group work emphasizes (I) acquiring knowledge of group structure and dynamics, (2) activities and programs in the group, and (3) the recording of proceedings. It is usually thought that individual diagnosis is not strictly the function of the social group worker, though there are times when he can throw light on the behavior or problems of in. dividuals. But, then, it is sometimes argued that he is functioning as a caseworker rather than a group worket. As far as the treatment part of field work is concerned, it is considered that the therapeutics of social group 
work are properly applied to cases referred by other workers. The caseworker finds a problem individual, diagnoses his problem and finds that a group experience might be better than an individual one. He may, therefore, recommend the individual to a group work agency which has the required set-up, activity and leadership. The group worker may then accept the referral, but the program for the client has in a sense already been worked out by the caseworker in consultation with the group worker. Thus, he alone is not responsible for treatment, but shares the burden with the caseworker. It should be pointed out that there are few agencies having formal group work programs. Most are recreation-centered; especially in the villages and slum areas, we have no structured agencies.

\section{Differences in Problems of Field Work}

The basic problems in field work faced by both India and the United States are: (I) to find suitable agencies for the placement of students, and (2) to find trained qualified supervisors for field work supervision. These problems are further accentuated in India as there are no clear-cut expectations worked out for the field work of students. Many students do not have a continuous placement in one agency and get very little supervision from the agency personnel, as most of the latter are not only overworked but have no training in the field of professional social work.

An important aspect of tield work planning is continuty of work in one agency to give the student more learning experiences and deep insight into various problems. A continued field work placement gives the student an opportunity to establish his relationship with the agency, group and other people with whom ne comes in contact, and he is able to see the results of his work. In most of the Indian schools a student is assigned for a term in an agency, and he has hardly been able to develop his relationship with the agency and the group before he is withdrawn and placed in another agency. Arguments are put that there are not enough opportunities for work experiences in the agencies. This could be overcome by a careful and detailed work plan for the student to give him useful and learning experiences. The field work agencies in the States do always prefer longer placements of students in the interest of service as well as learning. There the agency personnel set aside time for super. visory conferences and take full responsibilities for providing supervision to students. The agency staff carries out the normal program, and the presence or absence of the field work students does not seriously affect services or programs of the agencies. In India field work students often become the personnel for carrying out the agency program, and, with the stoppage of the work of students, the program comes to a standstill.

Where agency staff is not able to give the student adequate supervision, it is carried out by faculty members of the school. This increase in the faculty work load necessarily affects the quality of supervision. In some cases the teachers have to take direct leadership in developing an agency and running a program. Sometimes faculty members carry as many as fourteen students for supervision in addition to their regular duties of teaching and other work. In the United States an agency or a school supervisor would often be considered as having a full-time job with a work load of six to eight persons to supervise. It should be remembered, too, that while Indian faculty members are qualified for giving supervision, very few of them have had an opportunity to supplement their education by a work experience, and even fewer have had a chance to work under supervision of a more experienced trained worker.

Another difficulty we face in India is that it is the student in the agercy who sometimes has to dig out his own assignments and find his own work. The agency supervisor sometimes does not see the usefulness of the field work content of the student worked out by the school and wants to follow his own plan with an ultimate goal to meet the needs of the agency rather than training needs of the student.

One other great difference we notice in the American and Indian scenes is that very rarely in India is a student placed where his full time is devoted to only a casework, group work or community organization assignment. Almost always he is expected, in a single placement, to do work simultaneously in all three processes.

Another of our problems is that in many agencies field work is at an observational and not at a participant level. The course is designed in a different manner than in the United States. In India most of the schools of social work include in their training program courses like Labor Welfare and Personnel Management, Rural Welfare, Medical Social Work and Correctional Administration, which in some schools are referred to as specializations. special interest courses or the freld of concentration. For these courses a complete full year is allotted, if not for lectures and field work both, at least for field work. Courses on social sciences also take much time, but very little is allotted to methods courses. In America specializations are based on methods of social work, rather than through concentra- 
tion on the fields of work in which the student is expected to operate. It is felt that this arrangement necessitates different types of field work, and most of the students in the second year concentrate on other types rather than devoting their time primarily to developing competency and acquiring skills either in casework, group work or community organization.

\section{The Participant Returns to India}

After the return from the training program abroad, a participant in the CSWE India Project should be in a position to make contributions which will prove a valuable asset to the school which had sponsored him. He should be able to contribute to development of the curriculum and the field work plan of the school. He should also be able to play an important role and sometimes take leadership in seminars organized by the CSWE team in India for the teachers of the schools of social work to consider the various problems of social work education. With the help of the team consultants, some of the schools have been able to publish case records on social casework, social group work and community organization, and participants have contributed to such publications.

With the help of the consultant, various steps may be taken to overcome some of the problems raised by the participants. The following are some of the lines along which I, as a participant of the Delhi School of Social Work, have worked cooperatively with our consultant. First, faculty seminars are conducted to improve the quality of supervision and standardize the field work requirements of the students. Secondly, seminars for agency supervisors have been arranged to acquaint them with the requirements of the school and the learning opportunities to be provided to the students during their field work placements. Third, an attempt is being made to have continuity of field work by giving a student a longer period of placement, prefer- ably in one of the methods of social work, to develop a good understanding and adequate skills. Fourth, guide outlines have been drawn for record writing and supervisory conferences. Fifth, detailed expectation of field work requirements has been worked out to help the students and the supervisors in the placement and supervision of the student. Sixth, the number of agencies has been reduced by placing more students in one agency. Seventh, the mode of evaluation of a student's work has been improved and modified. Lastly, an attempt is made to integrate theory and practice to help the students to gain knowledge, develop attitudes and acquire skills to be a professional social worker.

In conclusion I should like to say - along the same lines as ideas expressed by Charlotte Towle - that my experience in professional social work education in the United States has enabled me to attain the objectives of professional education, in classroom and field, through definable areas of learning. These areas are: (I) an orderly way of thinking which approximates scientific method; (2) knowledge and understanding of normal human behavior and of psychology, with focus on developmental periods, cultural factors and social stress; (3) knowledge and understanding of health and disease, and the social aspects of illness, handicaps and preventive and remedial care; (4) knowledge and understanding of working relationships and their management; (5) knowledge and understanding of agency structure and function, the agency's place in the community, its coordination and collaboration with other agencies and institutions; (6) knowledge and understanding of the community in terms of how to use it - educational, health and welfare resources, its institutions, and its legal framework; and (7) knowledge of history and law and how to use it in the solution of social problems. 